\title{
The cold truth
}

\author{
A little foresight.
}

Monday Of course I'm furious with the woman. It's unprofessional. We all bounce ideas off our graduate students that we wouldn't dream of floating at a real seminar. Obviously Franklin picked up that stringresonance notion from young Hoggett after I'd tried it on him, and now she's published the thing. Not something you can prove, but I know.

It's tempting to give her a sniff at another tasty little problem - the one I suspect of being a trojan horse ...

Tuesday Always yield to temptation. I fed my esteemed colleague Dr Jane Franklin the germ of the temporoscope via anonymous e-mail. Let her waste her time on that.

It's my favourite dead-end idea out of science fiction: a time viewer that spies on any past scene, anywhere. At first I thought it was too absurd to write up without getting my reputation giggled to death. Then I started wondering why no one at all had published even a wisp of speculation about the tachyon entanglement mechanism that sounds such a plausible basis for the device. Einstein, Wheeler, Feynman, Witten, Coleman, Hawking: they all missed it. Or decided not to pursue it. Did the Time Police step in to change their minds?

Certain trains of thought may simply be bad luck to follow. Somehow I'd never cared to take this one too far.

Wednesday Thought Franklin looked a bit introspective at High Table last night. Has the temporoscope bug bitten her? Maybe just my imagination.

Passing the parcel was supposed to clear the thing from my mental in-tray, but it nagged at me through the small hours and wouldn't let me sleep. One point seems selfevident, even without solving the difficult (maybe insoluble) parts. It wouldn't work the way science-fiction writers would like, channel-surfing to view the dinosaurs, the Crucifixion, or all those gunmen scattered round Dealey Plaza in November 1963. No, you'd need a working temporoscope somewhere in the era to be viewed. The first machine built could never show a scene from before its initial switch-on. Great as a global surveillance device - if it worked - but utter pants as a time viewer.
None of this explains the feeling of dread I get when picking at this idea. Reminder to self, again: it's Franklin's problem now.

Thursday Hoggett was unusually dense in today's supervision. He seemed to have picked up the wrong mental toolkit for our topic, and kept harping on about mass-energy conservation in cases where this wasn't a useful approach. Afterwards it occurred to me that he'd had a morning session with Franklin. Could issues of energy balance be preying on her mind?

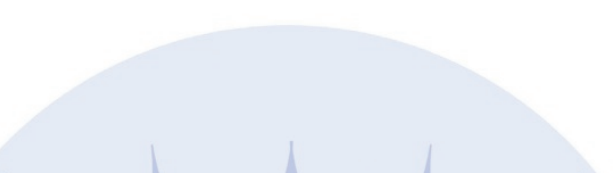

cold matter yield a little energy as they're thriftily fed into black holes, and so on. Now, instead, I imagine those parasites at the end of time basking in the glow of ever so many temporoscopes - sucking life and information out of the past.

It gets worse, because the time viewing schema implies the many-worlds view of quantum theory. You should be able to observe other strands in that endless garden of forking paths. Or, turning it around: the existence of the first temporoscope in a given universe-strand will expose that strand to the petrifying gaze of not only its own sheaf of futures but of every possible future. Any universe where a temporoscope is built will promptly die of cosmic hypothermia ... catching an everlasting cold.

If this happens, it's all Franklin's fault. To destroy the cosmos as we know it would be just like a woman.

Friday Another bad night. Dreams of Ragnarok and Fimbulwinter and a world overrun by frost giants.

Now at last I see why none of the physics giants - Einstein, Hawking and the rest - ever published a theory of time viewing. It's the anthropic principle all over again. Only the strands where the damned temporoscope was never built still contain life.

Although on principle I'm not talking to her, I believe I need to have a word with Dr Jane Franklin.

More e-mail. That's odd: an unsigned downhill from that point, and left me in a cold sweat. Oh dear. Every use of our hypothetical temporoscope must necessarily steal a little information, a little energy, from the past. An imperceptible amount, I'd blithely assumed.

But as someone said, eternity's a terrible thought: where's it going to end? Every future temporoscope should be able to observe the era of the first one. If you build a time viewer, you lay your present open to the hungry eyes of futurity. A trillion of them, a decillion, a googol? All leeching energy, photon by photon, from today's world and Universe.

In the evening I tried quite hard to get drunk, but the logic wouldn't go away. There's been a fair amount of speculation in science and science fiction about far-future survival as the cosmos totters towards its final, entropic senility. Husbanded dregs of message relayed by an anonymous re-mailer, ingeniously phrased to set me thinking about the possibility of a temporoscope ... It is, in fact, word-for-word identical to the e-mail I sent on Tuesday.

Either the woman has rumbled me or she's recognized a bad-luck problem and most ungenerously means to use a colleague as a catspaw. One must admit this shows a certain low ingenuity. I wonder if she could be persuaded to discuss matters over a meal? At the Raj Tandoori, perhaps. Something hot and spicy to keep away the cold.

\section{David Langford}

David Langford, a former physicist turned science-fiction author and critic, lives in a Reading house whose mantelpieces are crowded with 28 Hugo Awards. 